\title{
EN BUSCA DE LA IGLESIA AUTÓCTONA: LA NUEVA PASTORAL INDÍGENA EN LAS CAÑADAS TOJOLABALES
}

\author{
Jorge Valtierra-Zamudio
}

Resumen: Este artículo tiene como objetivo explicar el proceso de transformación de la acción pastoral de la diócesis de San Cristóbal de Las Casas, Chiapas, y la nueva fase en la pastoral diocesana, heredera de la "catequesis integradora" y de la teología de la liberación que ha llevado a una "nueva pastoral indígena". A través de un ejercicio etnográfico de la Misión de Guadalupe y su labor en las cañadas tojolabales, proporcionaré un acercamiento sobre la forma en que los agentes de pastoral han implementado estrategias frente a las dificultades para integrar esta pastoral y la meta de construir una Iglesia autóctona.

Palabras clave: Teología de la liberación, catequesis integradora, nueva pastoral indígena, agentes de pastoral, tojolabales, Iglesia autóctona.

Enviado a dictamen: 27 de junio de 2012

Aprobación: 02 de agosto de 2012

Revisiones: 1

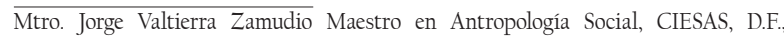
Doctorante en Antropología, CIESAS, D.F., Temas de especialización: antropología de la religión. Correo electrónico: jovaza80@gmail.com.
Abstract: Thispaper aims to explain the process of transformation of the pastoral action in the diocese of San Cristóbal de Las Casas Chiapas, and a new phase in the diocese pastoral action inherited from the so-called "inclusive catechesis" and the theology of liberation leading to a "new indigenous pastoral". Through an ethnographic search about the "Misión de Guadalupe" and its work in the "Tojolabal Cañadas" I will show how these missionaries have implemented different strategies so they can put into practice this new pastoral whose goal is building an Autochthonous Church.

Keywords: Theology of Liberation, inclusive catechesis, new indigenous pastoral, missionaries, Tojolabals, Autochthonous Church.

\section{Introducción}

T a historia de la Iglesia católica en Chiapas en el siglo XX, sobre todo de la diócesis de San Cristóbal de Las Casas, ha dado lugar a un sinfín de trabajos académicos, periodísticos y de otra índole, en los que descuella la figura del otrora obispo Samuel Ruiz García por su compromiso social con los pueblos indígenas. Sin embargo, "Samuel Ruiz es un referente pero no es la diócesis” (Figueroa, 2002: 130). Existen muchas personas antes, durante y después 
de él, involucradas en el proceso de transformación y desarrollo de la pastoral indígena de esta diócesis, en el que han influido una serie de ideologías locales y del exterior, circunstancias políticas y sociales a nivel global y local, y un proceso histórico complejo que caracteriza a la diócesis y al estado de Chiapas.

En la actualidad, aún se asocia a los misioneros o agentes de pastoral de la teología de la liberación con el levantamiento armado del Ejército Zapatista de Liberación Nacional (EZLN) ocurrido en enero de 1994. También se habla de una Iglesia católica con rostro indígena. Pero, salvo algunas obras que aportan un valioso material al respecto, ${ }^{1}$ son escasos los trabajos que rompen con esta idea y poco se habla de la acción pastoral actual, que aquí llamaré "nueva pastoral indígena" o "pastoral indígena renovada", y que forma parte de una nueva fase de la pastoral de la diócesis de San Cristóbal, heredera, por supuesto, de la catequesis integradora y de las teologías de la liberación e inculturación (Harvey, 2001; Morales, 2005 y Valtierra, 2009).

El anhelo de estos modelos de pastoral ha sido construir una Iglesia autóctona. Sin embargo, en la actualidad, el camino y los mecanismos para alcanzarla son distintos, empezando porque cada vez hay una menor tendencia a lo doctrinario y una acción pastoral politizada, y una mayor orientación a acciones que promuevan la autosuficiencia de los pueblos indígenas y la fidelidad a sus propias raíces culturales que, manifestadas en su religión, conlleven a la autoctonía de la catolicidad y no sólo a una Iglesia local. ${ }^{2}$

En el presente artículo intento explicar de manera breve el proceso de transformación teoideológica y teopolítica de la pastoral indígena de la diócesis de San Cristóbal de Las Casas que lleva a la fase de una pastoral indígena renovada. Para tal efecto, he tomando el caso de una región, Las Cañadas, en la Selva Lacandona, y una misión católica, la Misión de Guadalupe, en donde he hecho investigación etnográfica durante casi cuatro años. Esta región geográfica es conocida por el equipo de pastoral de la misión como "las cañadas tojolabales" porque es una zona que está conformada, en su mayoría, por comunidades tojolabales.

En un primer apartado presento una breve síntesis de los fundamentos que sustentan una ideología y praxis eclesiásticas - la teología de la liberación- a raíz de una serie de coyunturas políticas a nivel global que coinciden con cambios profundos dentro del organismo católico desde la década de 1960 que han influido mucho en el quehacer pastoral de la Iglesia católica mexicana, en específico la diócesis de San Cristóbal de Las Casas.

El siguiente apartado explica el proceso y evolución teopráctica de la diócesis de San Cristóbal de Las Casas, con Samuel Ruiz como obispo, y su legado, que ha dado una base firme para el desarrollo de otras pastorales, promovidas algunas desde otras partes de América Latina a partir de la catequesis integradora.

En un tercer apartado, hago un recuento de cómo esta catequesis integradora se va insertando en las cañadas tojolabales hasta el comienzo de su proceso de transformación y, finalmente, en el cuarto y último apartado abordo el caso específico de la Misión de Guadalupe, que ha intentado reintegrar la pastoral indígena en las cañadas tojolabales, lo que ha generado una serie de cambios y estrategias en el modelo pastoral para lograr una mejor recepción de éste y así lograr la anhelada Iglesia autóctona.

\section{De la doctrina a la praxis: arribo del liberacionismo a la Iglesia mexicana}

Hace años, el tema de la globalización se abordaba con términos como "capitalismo" o "imperialismo" indistintamente, a partir de los cuales se identificaban las principales causas de la desigualdad social y económica de las llamadas "periferias" (Giménez, 2000: 20), es decir, las naciones que rodean a los centros de concentración del poder. Esta, sostiene Giménez, es una de las razones por las que muchos movimientos a 
lo largo del siglo XX emergieron en busca de la denuncia contra el abuso y el dominio de los núcleos de poder.

Frente a esta atmósfera de desigualdad e inconformidad, la Iglesia católica no hizo oídos sordos. Desde mediados de la década de 1960, un sector de este organismo religioso asumió una postura comprometida social y políticamente con muchos de estos movimientos, basándose en una importante reforma de sus instituciones: el Concilio Vaticano II (1962-1965).

Es cierto que siglos atrás ya había posturas de la Iglesia en defensa de la gente que sufría desigualdad y pobreza, cuando otros sectores de la sociedad colonial gozaban de riqueza y privilegios a costa de la explotación de otros - como las de fray Bartolomé de Las Casas o fray Alonso de la Veracruz en el caso de México-. Pero se trataba de posicionamientos minoritarios y de mediana trascendencia si se equipara con la acción de un sector de la Iglesia en las décadas de 1960 y 1970 en lo que se conoce como teología de la liberación (Berryman, 1989; Dussel, 1995). Ahora bien, antes de la teología de la liberación las luchas de denuncia que se realizaban por iniciativa de algunos miembros del clero contemplaban un criterio, por lo general, asistencialista y doctrinario que no manifestaba una contundente perspectiva social como tal. Fue varios siglos después cuando la Iglesia católica fue modificando su carácter meramente doctrinario y lo elevó a una posición y perspectiva, primero social - con la encíclica Rerum Novarum-y luego política sustentada en los acuerdos del Concilio Vaticano II (1962-1965).

Este concilio causó gran efecto en la composición estructural de la Iglesia, que en realidad nunca ha sido monolítica, porque acentuó su heterogeneidad y las diferentes posiciones e intereses de cada uno de sus miembros. Estos documentos significaron toda una revolución y una serie de reformas que actualizaban el discurso político y la perspectiva de misión de las instituciones de la Iglesia frente a una acelerada modernidad que exigía una apertura del organismo eclesiástico hacia las coyunturas sociopolíticas y la diversidad sociocultural cada vez más evidenciada en el mundo (Hernández, 2006; Camp, 1998).

Mientras tanto, en América Latina el ambiente de lucha y descontento conformaba un escenario ideal desde el que podía tomarse el mensaje conciliar, que inspiró la dirección de la segunda conferencia episcopal latinoamericana celebrada en 1968 en la ciudad de Medellín, Colombia, y en donde se determinó como un reto eclesial poner en marcha una pastoral con bases progresistas y tomar la opción preferencial por los pobres. Asimismo, lo que pregonaba el Concilio Vaticano II era el diálogo con las culturas, lo cual fue muy tomado en cuenta en un continente en el que gran parte de su población, en estado de pobreza y explotación, estaba conformada por grupos indígenas y afrodescendientes.

Los documentos Gaudium et Spes y Lumen Gentium de Vaticano II, la encíclica Populorum Progressio (1967) y Medellín (1968), por lo menos en América Latina, no sólo fueron significativos para abrir espacios de discusión acerca de la situación a nivel global, sino para modificar gran parte de su doctrina - doctrina social cristiana - en una enseñanza social de la Iglesia que lleva en sí misma un tono absolutamente liberador (Blancarte, 1994: 8). ${ }^{4}$ La consecuencia de esto fue que un gran sector del catolicismo de corte oficial se alejó de su núcleo en las ciudades de blancos y mestizos y se aproximó al ámbito rural que era preponderantemente indígena, tomando en cuenta de forma paulatina su cultura expresada a través de sus antiguos cultos y religiones, los cuales sobrevivieron junto con el cristianismo en un amplio paisaje sincrético o de coexistencia religiosa (Dussel, 1998: 74). Pero no se llegó a este nivel de discernimiento de forma inmediata.

Es importante aclarar que el mensaje conciliar de diálogo con las culturas no se tomó como un diálogo intercultural. La Iglesia latinoamericana liberadora, es decir, de la teología de la liberación, asumió un 
firme compromiso social y político a favor del pobre y el oprimido, aun en contra de Roma. Sin embargo, no se identificó con una cultura en concreto. Esto se debe a que la Iglesia - y el cristianismo - aunque ha tratado de modificar esta tendencia, es por antonomasia universalizante y etnocentrista (Mariz y Theije, 2008). Esto significa que la teología de la liberación, a pesar de surgir de muchas discusiones dentro de los espacios que organizó la Iglesia y otros ámbitos académicos, como la Primera Declaración de Barbados en 1971, no enfocaba su lucha a una cultura en específico, sino a cualquiera que fuera "pobre".

El discurso y la praxis inspirados en la teología de la liberación no consideraban la diferencia cultural y étnica en ese entonces, ni se detenían en comprender las particularidades y necesidades de cada grupo, viendo la población de América Latina como un "todo" pauperizado y explotado uniformemente que había que liberar y asistir.

En México, en las décadas de los sesenta y setenta, Cuba y su proceso revolucionario tuvieron una fuerte influencia en la izquierda, y esto animó a un buen sector del episcopado a declarar los peligros que implicaba el comunismo; incluso ofreció ayuda al gobierno para oponerse a esa amenaza. Sin embargo, la relación entre una parte de la Iglesia posconciliar y los movimientos de izquierda empezaba a estrecharse.

Las actitudes intolerantes y violentas del Estado hacia movimientos de izquierda como la sangrienta represión a los movimientos estudiantiles acaecida en la Plaza de las Tres Culturas en Tlatelolco (1968) y a las afueras de la Escuela Normal Superior de México (1971), fueron eventos que impactaron a la Iglesia, sobre todo al sector simpatizante con la izquierda. Hubo opiniones encontradas; sacerdotes y religiosos que condenaban esos actos - sobre todo aquellos que tenían un vínculo estrecho con organizaciones estudiantiles y obreras, y unos pocos pertenecientes al alto clero- $-\mathrm{y}$ otros que pedían prudencia y no involucrarse en esos asuntos extraeclesiásticos (Concha, 1986: 88).
Esta coyuntura en México se aunó a lo obtenido en la segunda conferencia episcopal de Medellín en 1968 y en las discusiones posteriores: una simpatía de muchos miembros del clero hacia una posición progresista que dio lugar en la Iglesia mexicana a una suerte de escisión entre la jerarquía y los sacerdotes con ideas más progresistas "que marca una crisis dentro de la institución, en particular en los crecientes conflictos internos de autoridad y en la ruptura de la homogeneidad ideológica estable desde 1929" (Camp, 1998: 51), año en que culmina nominalmente la Cristiada y la política anticlerical.

Los efectos de Medellín en México coincidieron con un periodo en el que había fuertes cuestionamientos hacia el gobierno, la situación económica y la política. La Iglesia, pese a la diferencia de posturas ideológicas, encontró en Medellín una reflexión que, si no convenció a todos por completo, por lo menos sí logró que algunos jerarcas latinoamericanos modificaran sus posturas ideológicas, entre ellos Samuel Ruiz García por parte de México, que ya era obispo de la diócesis de San Cristóbal de Las Casas (1960-2000).

Además de estas fuentes de influencia, algunos autores atribuyen el cambio de jerarcas como don Samuel Ruiz al contacto estrecho que durante su gestión tuvieron con la multietnicidad de las comunidades indígenas de la diócesis y sus problemas. Pero también debe considerarse que la Iglesia en Chiapas pudo asumir su postura de denuncia por una política agraria que no había funcionado y por los abusos de poder de los gobiernos federal y local gracias a que, a diferencia del resto del país, la política anticlerical del Gobierno mexicano no fue tan profunda y se dio de una manera distinta. $^{5}$

Antes de Samuel Ruiz, el obispo Lucio Torreblanca (1944-1959) ya había notado una situación de explotación en la población indígena que no cesaba a pesar de las políticas agrarias. Seguían o surgían nuevos cacicazgos y la paulatina desaparición de las fincas dejaba a los indígenas aun sin la exigua protección que tenían 
cuando estaban acasillados. La Iglesia chiapaneca en esa época no había vivido el Concilio Vaticano II ni Medellín, pero Torreblanca, consciente de una realidad desfavorable para el pueblo indígena, vio la necesidad de comenzar, después de largos años de ausencia de la Iglesia, una acción pastoral indígena que se concretizó en 1952. ${ }^{6}$ Esta acción pastoral indígena fue continuada por don Samuel a su llegada en enero de 1960, ya en una época en la que se sentaban las bases de una Iglesia de los pobres y liberacionista.

\section{La diócesis de San Cristóbal de Las Casas y la catequesis integradora}

Es evidente que la pastoral indígena en Chiapas que surge durante la gestión del obispo Lucio Torreblanca en 1952, tenía una estructura de trabajo muy diferente a la de la época de Samuel Ruiz, empezando porque era más doctrinaria y asistencialista. Tampoco debe pensarse que fue la primera iniciativa doctrinaria de este tipo dirigida a los pueblos indígenas en el siglo XX, pues desde 1940 algunos organismos y grupos religiosos no católicos ya habían comenzado a actuar en esa tónica, como es el caso del Instituto Lingüístico de Verano (ILV) (Estrada, 2004: 204).

La importancia de la diócesis de San Cristóbal en la época de Torreblanca consiste en que, previo al Concilio Vaticano II, reflejaba una "Iglesia social" heredera de la Rerum Novarum. La característica de esta Iglesia es que dirigía su vista a la injusticia social chiapaneca, sobre todo a los indígenas que eran quienes conformaban una parte demográfica importante de la entidad.

Otra postura muy firme de la Iglesia en la época de Torreblanca, además de la conciencia social y, podría decirse, indígena, era el anticomunismo y la descalificación de la entrada y acción de otras confesiones cristianas (Ríos Figueroa, 2002). Es esto lo que heredó Samuel Ruiz. Pero, con el paso del tiempo, el discurso anticomunista se fue diluyendo e incluso su posición de rechazo a la acción protestante disminuyó.
Lo que Ruiz fortaleció bajo su gestión fue el trabajo pastoral con los indígenas. Para él, de hecho, fue la prioridad en su agenda de acción pastoral, de tal forma que no sólo fomentó una Iglesia de los pobres con una pastoral indígena, sino la construcción de una Iglesia con rostro indígena.

El periodo en que Samuel Ruiz estuvo al frente de la diócesis de San Cristóbal pasó por distintas etapas o fases de acción pastoral. No siempre fue una Iglesia con rostro indígena incluyente. Marco Estrada (2004 y 2007) ubica una primera etapa asistencialista y desarrollista que va de 1960 a 1968, y que es la herencia de una pastoral doctrinaria y dirigida a los indígenas por ser éstos los más pobres de la diócesis de San Cristóbal, no por ser indígenas simplemente. Esto significa que la Iglesia social, la de la Rerum Novarum, había asumido con el tiempo una opción preferencial por el pobre que se confirmaría más adelante en el Concilio Vaticano II. Pero esta iglesia de los pobres estaba más bien basada en la connotación moral y/o religiosa de pobreza en tanto actitud de humildad y fidelidad al contenido evangélico. Su misión era enseñar la palabra de Dios, pero no a través de una acción política y liberadora.

Los primeros años de la pastoral de Samuel Ruiz consistieron en dar continuidad al trabajo de su antecesor y hacerlo más amplio, por lo que promovió la fundación de escuelas de catequistas y formación cristiana que se ocuparon de instruir a los indígenas dentro del territorio que abarcaba la diócesis, en estudios bíblicos y otros trabajos y oficios. Uno de estos centros de formación de gran importancia fue la Misión de Guadalupe, fundada en 1962 en San Cristóbal de Las Casas, y dirigida por la congregación de los Hermanos Maristas de la Enseñanza.

La función de esta misión consistía en formar y preparar una gran cantidad de catequistas de distintas partes de la diócesis para dar continuidad al trabajo catequético, lo que era a veces imposible por la difícil geografía que obstaculizaba el trabajo de un muy 
escaso número de sacerdotes y religiosos en esa tarea. Los catequistas indígenas eran vitales porque podrían, además, comunicar lo aprendido en su propia lengua y con su propia gente, pero también paliaban la escasez de agentes de pastoral y sacerdotes. Así pues, comenzaría una labor distinta a la que había hecho la Iglesia católica en México a lo largo de casi cinco siglos.

Desde Torreblanca, el territorio de la diócesis era ya concebido como un territorio de misión y privilegió al clero local y a las órdenes religiosas que le apoyaran en su plan pastoral. Fue él quien le dio un carácter sistemático y organizado al quehacer pastoral. En este sentido, Ruiz sólo continuó con ese sistema. Pero, además de lo que se explicó en el apartado anterior con respecto a la coyuntura política, social y económica como motivos que influyeron en la puesta en marcha de una acción teopráctica distinta a la doctrinaria y asistencialista, existen algunos elementos que para el caso de la diócesis de San Cristóbal de Las Casas es de suma importancia considerar: la emergencia de una corriente ideológica y política del indigenismo del Estado mexicano; la inspiración a partir de la promoción desde el Vaticano de clérigos y religiosos indígenas en los distintos países africanos y asiáticos en donde comenzaban los movimientos anticolonialistas (Morales, 2005: 92); y el intercambio de ideas con el teólogo de la liberación Edgar Beltrán, quien planteaba la necesidad de hacer una nueva teología con una metodología de interpretación de la realidad social sustentada en teorías sociológicas del momento (Morales, 2005).

Surge así un cambio teoideológico que Marco Estrada (2004: 207) califica de liberacionista. Pero dos de los eventos de cambio de mayor importancia que le dieron a la diócesis de San Cristóbal un carácter inclusivo más que liberacionista, fueron la evaluación del ministerio catequístico en 1968 y el Congreso Indígena en 1974. Este fue el punto de partida de una pastoral que establecería como meta definitiva la construcción de una Iglesia autóctona.
En el primer caso, la evaluación del ministerio catequístico destaca el testimonio expresado por Pablo Iribarren en el que los catequistas indígenas advierten que la Iglesia y la palabra de Dios contienen el mensaje para salvar sus almas, pero faltaba saber cómo salvar sus cuerpos que padecían hambre y pobreza (De Vos, 1997: 95; Estrada, 2004: 208). En el segundo caso, se trata de un congreso que se distingue no sólo por trabajar temas de suma importancia como educación, salud, tierra y justicia, sino por haber sido un espacio en el que los líderes indígenas alzaron la voz y pidieron que se legalizaran las tierras comunales, denunciaron las invasiones a sus tierras por los rancheros, la corrupción de los funcionarios del departamento de asuntos agrarios y colonización, los abusos de los intermediarios; exigieron educación en sus idiomas y la defensa de sus culturas, etcétera (Harvey, 2001: 96). ${ }^{7}$ Esto impactó a Ruiz y determinó la delimitación de la diócesis como un actor político a la par de un movimiento campesino indígena cuyos líderes eran o habían sido por lo general catequistas indígenas.

Estos eventos fueron muy oportunos en una época aún de mucha desigualdad social, aunados a otras circunstancias fuera de la diócesis de San Cristóbal y a una fuerte influencia también de las ciencias sociales en el pensamiento de Ruiz que se resumieron y discutieron en el Primer Sínodo Diocesano en 1975. De esta manera, la etapa liberacionista trascendería a otro modelo pastoral basado en: 1) la encarnación del Evangelio en las culturas indígenas de la región sin desplazar sus costumbres, tradiciones y religiosidad; 2) una nueva forma de catequizar en donde la comunidad participara y se enfocara en la solución de los problemas comunitarios y en el análisis de las circunstancias de opresión económica y política; y 3) una mayor presencia o acompañamiento de los agentes de pastoral in situ. Esto, en síntesis, es lo que se conoce como "catequesis integradora", es decir, no es exclusiva del clero sino incluyente; su centro de atención no es el individuo sino la comunidad, y adapta el mensaje 
cristiano a las particularidades socioculturales y sociorreligiosas.

Esta catequesis también se basa en lo que conformaría más adelante la teología de la encarnación o inculturación bajo el mensaje del documento Ad Gentes del Concilio Vaticano II acerca de la inserción de la Iglesia, similar al plan de la Encarnación, para una acomodación a las costumbres más profundas en cada territorio sociocultural (Ad Gentes, 22). ${ }^{8}$

La catequesis integradora y el plan de la Encarnación de la Palabra de Dios no se alejaron, sin embargo, de ciertos tintes liberacionistas. Prueba de ello es que fueron un motor para el desarrollo de bases de apoyo en las comunidades y para el logro de formas de representación más autónomas. De ahí que algunos autores consideren a los agentes de pastoral como "caudillos potenciales". ${ }^{9}$ Pero sí hubo modificaciones en las prácticas pastorales que dentro del liberacionismo contenían características negativas. Un ejemplo de esto son los cursos de formación de catequistas que al principio suprimían muchas prácticas culturales autóctonas para superponer modelos occidentales de cambio social. La modificación que se hizo al respecto fue la consideración de los rasgos culturales étnicos en los que debía encarnar la palabra de Dios, y desde ese punto empezar a construir una Iglesia autóctona, es decir, una iglesia construida por y para los indígenas. ${ }^{10}$

El cambio de la tónica pastoral de la diócesis se vio concretizado con la reubicación de algunos de sus colaboradores en puntos estratégicos para tener un mayor acceso a las comunidades. Uno de estos casos es el de la Misión de Guadalupe, que se trasladó a la ciudad de Comitán de Domínguez para colaborar junto con la Misión Tojolabal — conocida como La Castalia — en la catequesis de campesinos tojolabales en la "zona fría". Una vez allí, los agentes de pastoral notaron que su radio de acción debía abarcar un territorio mayor porque muchos tojolabales habitaban en la Selva Lacandona, donde se encuentra la subregión de Las Cañadas. A raíz de lo que se conoce como la colonización de la Lacandona, valdría la pena hacer una breve síntesis porque éste fue también un escenario propicio para que la catequesis integradora alcanzara su máxima expresión.

\section{La catequesis integradora en las cañadas tojolabales}

La retirada de las compañías madereras tabasqueñas y extranjeras de la Selva Lacandona en las primeras décadas del siglo XX la había dejado libre para su colonización. El inicio del poblamiento de esta zona se dio en el periodo presidencial de Lázaro Cárdenas (19341940) y culminó alrededor de 1970. Pero esta colonización se debió a varios factores, según sugieren especialistas en el tema.

Neil Harvey explica que en esta época de reparto agrario, y quizá antes, uno de los factores que orilló a la colonización de la Lacandona fue la formación de una comunidad revolucionaria institucional y un caciquismo indígena que obligó a muchos otros indígenas a migrar y colonizar las tierras disponibles en la selva (2001: 74). Jan De Vos (2004) indica que gran parte de este proceso colonizador se da a partir del poblamiento de la selva por parte de campesinos sin tierra, de los que un $80 \%$ provenía de las fincas. En realidad, el motivo básico de la colonización tiene que ver más con solucionar el problema de la escasez de tierra disponible, lo que conlleva hambre, aunque también existe otro sentido que es el de buscar una vida y comunidad nuevas más allá del sistema de haciendas con peones acasillados, es decir, encontrar una autonomía que se ha logrado a partir de la comunidad ejidal y la organización de bases de apoyo en donde la diócesis de San Cristóbal debió influir de forma definitiva (Estrada, 2004: 201). Sin embargo, la colonización no sólo significó la ocupación de tierras, sino un proceso complejo de recreación de la identidad étnica.

Lo que intervino para esta recreación identitaria fue la labor concientizadora de la Iglesia católica, el activismo de grupos de izquierda de inspiración 
maoísta, la instalación de campamentos de refugiados guatemaltecos, la conformación sociopolítica de las comunidades que se establecían y, sobre todo, una militancia y credo compartidos (De Vos, 2004: 11). Fueron estos últimos factores los que propiciaron la recreación de una nueva identidad étnica en un escenario multiétnico que la pastoral contribuyó a homogeneizar en la categoría de "hermanos" de fe, y que ha sido un importante eje de unidad política (Leyva, 2002: 399; Leyva y Asencio, 1991: 43).

La consolidación social de las comunidades en la praxis se fue dando, en gran medida, por la acción pastoral de la diócesis que asesoró a los indígenas, aunque también participaron otros grupos no religiosos de izquierda. Esta asesoría en conjunto coadyuvó a que las comunidades alcanzaran un alto grado de estructuración sociopolítica, surgida, entre otros factores, por la concientización nacida de la evangelización y la asesoría de grupos organizados por algunos religiosos, y también por militantes y guerrilleros de las Fuerzas de Liberación Nacional en las décadas de 1970 y 1980 (De Vos, 1997: 90; Leyva, 2002: 388; Estrada, 2011).

Entre los actores religiosos involucrados, destacó la participación de los jesuitas de la Misión de Bachajón y los dominicos de la Misión de Ocosingo, aunque los maristas de la Misión de Guadalupe, a su llegada a Comitán en la década de 1970, tuvieron una acción muy importante en la zona de Las Cañadas que aún era poco explorada. El interés de la diócesis en Las Cañadas y la franja finquera en los límites de la Selva Lacandona, se debía a que era la zona más pobre de la entidad, y en esa época la "opción por el pobre" había cobrado mucha fuerza.

Un factor que debe considerarse en esta zona en el proceso de transformación pastoral en esta región es la multietnicidad, porque es parte de lo que complicó el quehacer pastoral que debía adaptarse a las características de cada grupo étnico. Pero esta multietnicidad de las Cañadas, más que verse como un gran reto para la catequesis integradora de la diócesis, era una oportunidad para comenzar a construir la anhelada Iglesia autóctona.

El panorama en Las Cañadas es complejo porque no se consideraba hasta hace poco que los individuos que ahí habitan presentaran características culturales muy distintas entre sí. Sólo se hacía una diferenciación basada en la lengua que hablaban. Al norte de Las Cañadas, por ejemplo, se ubica una mayoría de población tseltal, mientras que en las cañadas del municipio de Las Margaritas la mayor parte de la población es tojolabal. Sin embargo, el acercamiento etnográfico me ha hecho ver que no todos los tojolabales son iguales como para clasificarlos dentro de un mismo grupo, empezando por la memoria histórica y las costumbres que llegan a variar mucho entre comunidades de una zona y otra.

De cualquier forma, estas características que en realidad poco se han trabajado o tomado en cuenta desde las ciencias sociales o desde el trabajo pastoral, han hecho difícil la comprensión de la complejidad de Las Cañadas tojolabales y sus habitantes. Por ejemplo, el conocimiento ancestral de las plantas medicinales no llega a ser tan profundo como se supondría por los efectos de la colonización, es decir, por el hecho de que no son sus tierras originarias. Se fueron asentando poco a poco y sus rasgos culturales se han ido transformando a partir de su nuevo entorno natural y de la memoria histórica más o menos clara que conservan.

En el caso, por ejemplo, de la religiosidad autóctona, ésta no se presenta de la misma manera que en otras comunidades o zonas de la diócesis. Esto se debe, al igual que ocurre con el conocimiento y manejo de su entorno natural, a que estuvieron largo tiempo acasillados en las fincas, lo que los mantuvo "aislados". Es decir, el proceso de aculturación en los tojolabales fue muy lento y paradójicamente los conservó como grupo social(Ruz, 1992; Mattiace, 2001; Estrada, 2007).

Bien es sabido que la religiosidad autóctona, como en el caso de muchos tseltales, tsotsiles u otros grupos 
"mayenses" del estado, es producto de la pérdida de preponderancia del clero después de las Leyes de Reforma en 1856, es decir, el abandono de los "pueblos de indios" implicó una gran oportunidad para los indígenas de recrear muchas costumbres, "partiendo de elementos coloniales y prehispánicos ingeniosamente adaptados a la situación de campesinos decimonónicos" (De Vos, 1994: 72). Esto no ocurrió así en el caso de los tojolabales, que durante esta época permanecieron acasillados y cuya religiosidad era en suma tradicional."

Es verdad que en Las Cañadas pudo haber un sector que aprendió a "recibir lo a ellos predicado y hacerlo suyo" (De Vos, 1997: 100) en un proceso de reinterpretación religiosa, pero en la zona tojolabal el caso es distinto y lo dice su misma historia en la finca, donde conservaron un ritual cristiano más tradicional, administrado muchas veces por el propio patrón, que se reafirmó con la doctrina de los cursos de catequistas de la década de 1960. Sin embargo, sí existen algunos elementos autóctonos que se conservaron por tradición como cuando participan en las romerías rumbo a su lugar mítico de origen, San Mateo Ixtatán, Guatemala (Mattiace, 2001; Ruz 1992; Gómez, 1999). Pero no se trata precisamente de una religiosidad autóctona. Al respecto, refiere un habitante de la comunidad de Río Corozal en Las Cañadas cuando le pregunté por el culto a la "madre tierra" y al altar maya como parte de su religión:

[...] mire hermano. Mi religión es la católica; es la Palabra de Dios. Pero respetamos el agua y la tierra porque nos da comida. Agradecemos a la naturaleza con nuestra palabrita a Dios, prendemos una candela... Pero no muy entiendo la cruz maya o por qué semos mayas. Quiere explicación pues... (Amador, Río Corozal, 14 de septiembre de 2008).

Desde la perspectiva de los agentes de pastoral, la interpretación difiere un poco, pero se reafirma que en Las Cañadas no hay una práctica religiosa autóctona per se dentro de la dinámica recreada por la pastoral indígena: "Aquí en Las Cañadas es distinto. Los hermanos no hacen altar maya, aunque sí hacen sus cultos, oran al olom ja' [ojo de agua], a las cuevas, la ceiba" (Jorge Paz, 1 de febrero de 2011).

La diferencia que se observa en estos aspectos, la religión y la historia del pueblo tojolabal, es un indicador de la dificultad para poner en marcha e integrar una pastoral indígena renovada como en otras áreas. En su momento, la catequesis integradora tuvo mucho éxito en Las Cañadas, sobre todo en cuanto a la organización sociopolítica que se articulaba entre la década de 1970 y principios de 1990 con diversas unidades ejidales, en lo que se conoció como Unión de Uniones. Pero después de 1994 esta unión se dividió en cinco organismos diferentes, entre los que se encontraba el EZLN. A partir de entonces, muchas comunidades de Las Cañadas perdieron su autonomía (Leyva, 2002) y la catequesis integradora fue debilitándose considerablemente.

La fase a la que trascendería la catequesis integradora se iría concretizando después de un margen amplio de tiempo entre discusiones, reflexiones y en espera de un ambiente más favorable. Esta nueva fase, la de la pastoral indígena renovada, tenía una fuerte base en la catequesis integradora en cuanto a ser inclusiva, seguir la opción por el pobre y tener en mente la inculturación del Evangelio; pero ponía más énfasis en alcanzar una Iglesia autóctona a partir de la identificación de otros problemas fundamentales, y no necesariamente teopolíticos, como la resolución de problemas en materia de salud, ecología, cultura y educación.

\section{Ecos de interculturalidad: la nueva pastoral indígena en las cañadas tojolabales}

La acción pastoral en las cañadas tojolabales puede entenderse a partir de dos momentos distintos, es decir, uno anterior y otro posterior a la catequesis integradora, y a partir de la actividad de dos misiones que abarcan estas dos fases: la Misión de Guadalupe y 
La Castalia. Ambas misiones han colaborado a lo largo de más de cuatro décadas en proyectos que no sólo están enfocados a la evangelización de las comunidades tojolabales, sino también a la organización de talleres de oficios diversos, con el fin de otorgar herramientas útiles para los tojolabales de acuerdo con su vida cotidiana y su entorno natural y social.

Esta mecánica pastoral fue significativa porque empezaba a modificar su carácter doctrinario propio de la década de 1960 y parte de la de 1970 (supra), por uno más ad hoc a las necesidades y realidades de las comunidades indígenas. La Misión de Guadalupe, por su parte, abría un espacio en el que los cursos de catequistas y oficios seguían impartiéndose, mientras La Castalia hacía lo propio e instalaba desde principios de los años setenta talleres de costura y otros oficios, así como programas de alfabetización.

Con el tiempo, el área de trabajo de estas misiones debió dividirse debido a la gran cantidad de comunidades tojolabales que había en el Valle de las Margaritas, Comitán, Independencia y, sobre todo, en las inaccesibles cañadas de la Selva Lacandona. Así, la Misión de Guadalupe dividió su foco de acción en nueve zonas, caracterizada cada una de ellas por ciertas condiciones geográficas, étnico-culturales y lingüísticas. Hoy las cañadas tojolabales son parte, casi en su totalidad, de suárea de trabajo, mientras que La Castalia más bien trabaja con comunidades más cercanas a la ciudad de Comitán y en el Valle de las Margaritas.

Entre los grandes obstáculos para la puesta en marcha de un plan pastoral en Las Cañadas, no se encontraban precisamente las organizaciones ejidales o la presencia de las Fuerzas de Liberación Nacional, a las que muchos catequistas, por cierto, se integraron. En un principio, el obstáculo mayor era el difícil acceso a esta zona. La catequesis integradora fue exitosa por la formación de catequistas indígenas que llevarían el mensaje evangélico. Pero, además, esta formación fue la base de la emergencia de líderes que, a la postre, se organizaron y participaron en estos movimientos de liberación, por lo que existía un cierto agradecimiento y respeto hacia los agentes de pastoral católicos y sus enseñanzas, aunque no creían que fueran suficientes para resolver sus problemas (Estrada, 2007: 298). Sin embargo, hubo otros factores que complicaron el trabajo pastoral aún antes de la salida de Samuel Ruiz de la diócesis. Entre otros, se pueden considerar la lucha armada y la presencia del ejército en los alrededores de Las Cañadas, el constante cambio de agentes de pastoral y sus visitas irregulares a estas comunidades por las mismas circunstancias y la enorme proliferación de otros grupos cristianos no católicos que han traído, en consecuencia, una división comunitaria.

La comunidad tojolabal de San Arturo las Flores es un buen referente de la pastoral en Las Cañadas y de los obstáculos a los que se ha enfrentado el agente de pastoral que trabaja en esta zona: ${ }^{12}$

San Arturo es uno de tantos casos en esta zona. Ellos se quejan de que no había acompañamiento de los pastorales de antes, pero no era tanto la lejanía, que de por sí es muy pesado el camino, sino que había dificultades porque estaban los zapatistas por ahí; luego, el ejército andaba rondando la zona y eso era muy peligroso. También la llegada de los hermanos protestantes que le decían a los hermanos [tojolabales] que el catolicismo no era bueno, y luego el diácono de la comunidad, pues no tenía ya mucha influencia por toda la división ideológica y de criterio que zapatistas y protestantes crearon en esta región (Jorge Paz, 26 de marzo de 2011).

A lo largo del texto he usado el término "nueva pastoral indígena" para referirme a aquella que se desarrolla después de la catequesis integradora liberacionista en busca de un camino distinto de liberación para contrarrestar la situación de división comunitaria, en este caso en las cañadas tojolabales, y que desequilibra su sociedad y entorno en todos los sentidos. La mecánica de esta pastoral se diferencia de la catequesis 
integradora por estar menos involucrada en una acción política de adoctrinamiento cristiano o en el combate a grupos no católicos. He aquí las palabras de una agente de pastoral de la Misión de Guadalupe, que llamaré con el pseudónimo de "Reina":

[...] aunque había cierta simpatía por las causas del EZLN - sobre todo la de los tojolabales, no tanto Marcos- no todo podía arreglarse con la lucha armada. Se tenía que lograr un pueblo tojolabal autosuficiente de toda institución, sin necesidad de violencia; se tenía que buscar la manera en que ellos recuperaran su dignidad. Se había avanzado con la pastoral indígena después del congreso de 74, en que no sólo se llevaba la Palabra de Dios, sino se orientaba a una organización social que era necesaria. Pero se debía poner más atención en lo que se le ha quitado desde hace años, siglos y con tanto sufrimiento: su cultura. La Iglesia Autóctona representa eso. La cristiandad de los hermanos indígenas debe expresarse desde su cosmovisión, desde su manifestación religiosa, desde su vida. No necesitan que el Estado esté presente en su vida o que se les diga cómo rezar. Esa etapa ya pasó. Entonces, la Misión, porque ellos siguen buscando la presencia de la Misión, debe renovar la pastoral indígena, apoyar con una educación, una orientación, un acompañamiento, no una imposición; romper con los vicios y dependencias que se han creado a lo largo del tiempo. Es ésa la pastoral indígena que se necesita, una con nuevos bríos. Es ésa la organización que se requiere y que debe perdurar. Lo que perdura es el Reino de Dios, no un régimen antigobiernista que ayuda, pero no soluciona" (28 de septiembre de 2008).

La nueva pastoral indígena en Chiapas ha retomado algunos aspectos de la catequesis integradora y ha hecho mayor énfasis en la noción de inculturación y en la Iglesia autóctona. Pero, al mismo tiempo, ha cambiado la noción del indígena pobre e infantil, así como las vías para lograr su liberación. La nueva pastoral indígena en la Misión de Guadalupe no consiste en "asistir" y "dar" al tojolabal, sino en proponer soluciones para valerse por sí mismo y programas que frenen la devastación ecológica para que ellos puedan vivir de su entorno natural sin consumir productos manufacturados o depender de subvenciones otorgadas por el Estado, o para comprar agroquímicos, nixtamal, medicamentos $\mathrm{u}$ otros productos que su entorno no les proporciona de forma natural..$^{13}$ Sin embargo, esta misión ha trabajado en identificar cuáles son los problemas de los tojolabales, incluyendo Las Cañadas, y comprenderlos cultural y socialmente.

Los resultados iniciales de esta búsqueda indicaban la necesidad de discernir la tojolabalidad, es decir, su cultura, su cosmovisión, su pasado, su realidad, etc. Habiendo poco conocimiento sobre el pasado tojolabal, se cayó fácilmente en la reinterpretación cultural, su asociación con elementos y circunstancias asociadas a un pasado histórico y religioso glorioso que dista mucho de la propia memoria tojolabal y los resultados de investigaciones serios al respecto, empezando por categorizarlos como mayas en general en una suerte de panmayanización. Existen algunos tojolabales que llegan a rechazar los elementos que se supone que les pertenecen porque no los consideran como suyos. Otros los integran momentáneamente, pero regresan a su ritualidad tradicional en una suerte de resistencia velada (De Vos, 1994: 68).

La Misión de Guadalupe ha identificado un problema mayor a resolver que es el de la comunicación para conocer y entender las necesidades e intereses de los tojolabales. Ahora, la comunicación es una prioridad en la agenda de la misión y la primera iniciativa es buscar que los agentes de pastoral aprendan la lengua tojolab'al no imitando el modelo de trabajo de otras confesiones no católicas, sino con el objetivo de comprender mejor su cultura, sus conocimientos ancestrales - como herbolaria, la forma en la que trabajan la tierra- y su 
mecánica sociocultural que no podría entenderse igual en español que en tojolab'al.

Esto conforma, entonces, una transformación importante y una nueva etapa del proceso pastoral de la zona sureste de la diócesis de San Cristóbal de Las Casas que aún está en proceso de transición y consolidación. En lo personal, puedo identificar como punto de origen los cambios que el movimiento armado zapatista trajo a la zona y que propiciaron una situación delicada que menguó la acción pastoral por un periodo de tiempo suficiente para reflexionar e identificar otros problemas de fondo más allá de la cuestión de la tierra y la autonomía de las comunidades. Ya avanzada la década del 2000 se vio con más claridad que el seguimiento de la encarnación de la palabra de Dios y la inculturación como tal eran vividas por los agentes de pastoral de otra forma. Además de la Palabra de Dios, ellos mismos eran los que se inculturaban (Valtierra, 2009), y era necesario ese proceso para comprender al otro. La mecánica, entonces, era considerar esos elementos de la catequesis integradora, de una inculturación in situ, y encontrar los "nuevos bríos" de los que habla Reina (supra) en la pastoral indígena.

La apuesta de la nueva pastoral indígena y el proyecto de comunicación de la Misión de Guadalupe es hacer una nueva reflexión alrededor de esta inculturación in situ e in praxis; elegir otros caminos de liberación basándose en el diálogo con los tojolabales, transformar incluso la perspectiva de otredad que se tiene del tojolabal, y emprender planes de trabajo no sólo con el equipo de pastoral, sino en conjunto con los tojolabales. Pero para eso se tiene que establecer primero una interacción misionero-indígena que logre cimentar de forma firme las bases de una interacción catolicidadtojolabalidad, es decir, una Iglesia autóctona.

\section{Consideraciones finales}

El proceso de transformación de la pastoral indígena de la diócesis de San Cristóbal de Las Casas ha dado como resultado la implementación de una pastoral indígena renovada a partir de una reflexión a través del tiempo y de la improcedencia de una ideología liberacionista homogénea en un entorno pluricultural y pluriétnico. Pero también a partir de la identificación de problemas ecológicos, identitarios y económicos en las comunidades, sobre todo por la dependencia de elementos externos que no buscaron o no pudieron evitar el movimiento zapatista ni la catequesis integradora, tales como los programas gubernamentales de ayuda, el uso de agroquímicos, la tala inmoderada, etcétera, que persisten en la actualidad y conforman el motivo principal que los mantiene sujetos a otras instituciones.

La meta inmediata de la nueva pastoral indígena en la praxis es lograr que las comunidades tojolabales no dependan, incluso desde una perspectiva autocrítica, del etnocentrismo de las instituciones ni de los lineamientos de la Iglesia católica. Esto ha implicado un trabajo arduo que, al parecer, ha tenido poco éxito en algunas zonas, sobre todo en las cañadas tojolabales. Por lo mismo, la conclusión a la que las misiones que trabajan en estas zonas han llegado es que urge establecer escenarios en los que las comunidades indígenas puedan desarrollar sus propias estructuras sociales, culturales, productivas y sociopolíticas, sin la dependencia del Estado, el activismo o las iglesias, sean la católica u otras.

Merecería la pena mencionar que los obstáculos identificados que han impedido un rotundoéxito de esta nueva pastoral indígena en Las Cañadas se relacionan con la falta de discernimiento sobre la cultura tojolabal y sus necesidades, pues de esa forma no se puede saber cuál es el bien común que debe alcanzarse. En algunas comunidades de Las Cañadas ya se manifiestan algunos problemas que padecen comunidades más cercanas a las ciudades, como la dependencia creciente de recursos materiales, la devastación ecológica o el desplazamiento lingüístico. Estos son aspectos por los que la Misión de Guadalupe se ha mostrado preocupada y por ello 
busca integrarlos en su quehacer pastoral apoyándose en técnicos y organizaciones no gubernamentales.

Estos proyectos, menos politizados y más dirigidos a la autosustentabilidad y emancipación de las comunidades tojolabales, se llevan a cabo a la luz del mensaje cristiano como un ejemplo de acción cristiana, no como una doctrina acompañada de proyectos altruistas y que podría fungir como proselitismo religioso. Se dirige a la implementación de acciones en beneficio de las comunidades indígenas y no a la confrontación y desarticulación de otros grupos religiosos, partidistas o activistas con ideologías progresistas y antirreligiosas como en etapas previas. La nueva pastoral indígena intenta ser una respuesta a las necesidades de las comunidades indígenas, pero busca a su vez no ser una imposición de la Iglesia como ha sucedido a lo largo de la historia.

Pareciera, sin embargo, que la intención de esta pastoral de resolver conflictos intra e intercomunitarios, de restablecer la cohesión social, de revertir los efectos de la devastación ecológica, etcétera, cae en una acción de reeducación. Esto lo ha sabido identificar el equipo de pastoral de la Misión de Guadalupe y se ha discutido la posibilidad de focalizar esta nueva pastoral indígena a partir de un trabajo analítico más minucioso en relación con la cultura.

Si bien el anhelo de esta pastoral es la construcción de la Iglesia autóctona, la principal acción a la que se enfoca la misión para lograrlo es comprender la tojolabalidad, y esto ha dado lugar a que haya un mayor interés en conocer la historia tojolabal y su lengua para poder comunicarse, es decir, dialogar o acordar, desde sus referentes culturales y su perspectiva, cuáles son las necesidades e intereses que tienen y en los que quieren que la misión les apoye.

En el caso de las cañadas tojolabales pareciera que urge la puesta en marcha de esta acción, pues gran parte de lo que han expresado los tojolabales de esa zona es que lo que quieren es una presencia más constante de los agentes de pastoral en sus comunidades, dado que esto "anima a la gente, se acerca más a la ermita y se olvida de convertirse a otra religión" (Ramiro, tojolabal de San Arturo las Flores, 14 de septiembre de 2008).

Quizá una de las debilidades de esta nueva pastoral indígena que, dicho sea de paso, muchos científicos sociales y activistas también tienen, se relaciona con la idealización y esencialismo hacia los tojolabales que conlleva una reinterpretación de su cosmovisión, cultura e historia, partiendo de un pasado glorioso que dista mucho de sus características socioculturales y sociohistóricas. Pero lo que es un hecho es que se trata de una acción pastoral que está aún en proceso de consolidarse y que cada vez está más abierta a dialogar con otros actores sobre teorías y corrientes ideológicas útiles para la estructuración de un plan de acción dentro de los límites del respeto a la cosmovisión y a las culturas étnicas.

\section{Notas}

${ }^{1}$ Una obra fundamental es la de Marco Estrada (2007) sobre la comunidad armada rebelde y el EZLN. Dedica buena parte de este libro a la historia de la Misión de Guadalupe y su trabajo pastoral. También, un artículo del mismo autor sobre la construcción del reino de Dios a través de la catequesis y la pastoral en Las Cañadas de la Selva Lacandona (Estrada, 2004). Otras obras importantes sobre la diócesis de San Cristóbal y el diaconado permanente son las de Ríos (2002), Mosqueda (2011) y Morales (2005).

${ }^{2}$ La noción de Iglesia autóctona aparece en el Concilio Vaticano II. En el documento Ad Gentes 6 y 22, se habla de iglesias particulares jóvenes o iglesias autóctonas particulares como aquellas arraigadas en sus costumbres y culturas. Esta noción ha cambiado con el paso del tiempo. En el momento álgido del liberacionismo latinoamericano, se entendía como lo originario que aplicado a la Iglesia se refiere a la fidelidad con las propias raíces culturales (Marzal, 1973: 
107 y 108). Ahora conlleva otra perspectiva que para la nueva pastoral indígena es el concepto de comunidad en armonía con el entorno natural y cultural, sin estar separada de la catolicidad.

${ }^{3}$ La llamada "Iglesia social" tenía que ver con una política social que la Iglesia católica concretiza a finales del siglo XIX en la encíclica Rerum Novarum, promulgada por el papa León XIII el 15 de mayo de 1891. Ésta presenta la postura de Roma acerca de la situación laboral de aquella época, apoyando la formación de uniones y sindicatos que garantizaran el bienestar de los trabajadores y obreros.

${ }^{4}$ Un aspecto importante que poco se ha considerado en la literatura sobre el tema es la encíclica Populorum Progressio que, dos años después de los acuerdos del Concilio Vaticano II, Paulo VI promulga, provocando un conflicto de autoridad al interior de la Iglesia porque trata del creciente desequilibrio entre los países ricos y pobres, critica el neocolonialismo, el capitalismo y alienta la cooperación entre los pueblos y el derecho de todos al bienestar. Esta encíclica es el marco previo a la CELAM de Medellín 1968 (Concha, 1986: 65-86).

${ }^{5}$ La represión del catolicismo en Chiapas tiene que ver con una fuerte influencia y apoyo del tabasqueño callista Tomás Garrido, pero el ambiente de represión se ejerció allí sobre todo entre 1933 y 1935. Para 1940, las relaciones entre el gobierno de Chiapas y la Iglesia ya se habían restablecido. No hubo un largo periodo anticlerical tan restrictivo como en el resto del país que diera lugar a que la Iglesia guardara silencio y actuara al margen de lo que exigía el gobierno.

${ }^{6}$ Entre la salida del obispo Francisco Orozco y Jiménez en 1913 y la llegada de Lucio Torreblanca en 1944, los efectos de la "desfanatización" del maximato, las políticas anticlericales del Estado mexicano y la escasez del clero por la misma situación, dieron lugar a la imposibilidad de plantear una vida pastoral. Hubo destierros y una acción débil de la Iglesia, la cual en realidad no representaba un peligro significativo para el Estado (Ríos, 2002: 50). Durante esta época se puede pensar que no había una presencia de la Iglesia católica en Chiapas, sino hasta el periodo de Torreblanca en el que éste pone en marcha un plan de doctrina cristiana dirigida a los indígenas en 1952, y al que dio continuidad Samuel Ruiz (Morales, 2005; Ríos, 2002).

7 Para más información sobre este congreso puede consultarse la obra de Neil Harvey (2001), así como la de Morales (2005), quien trata el tema con mayor análisis. ${ }^{8}$ De forma muy general, la teología de la inculturación se centra en encarnar el Evangelio en todas y cada una de las culturas, pero también a los agentes de pastoral y la Iglesia, buscando quitarse todo el ropaje occidental que amenace con anular e impedir el desarrollo y la manifestación de las formas culturales y religiosas autóctonas (Valtierra, 2009).

${ }^{9}$ Neil Harvey (2001: 88) habla de los agentes de pastoral como caudillos potenciales por sus características de líderes naturales que los hacen convincentes y obtienen la confianza de la gente para organizarse. Es un hecho que desde la versión de algunos catequistas y diáconos tojolabales de Las Cañadas que simpatizaron con movimientos como el EZLN, el papel de los agentes de pastoral en los años setenta y ochenta era formarlos y eso conllevaba enseñarles a organizarse, a saber luchar por sus derechos y a ser líderes (San Arturo las Flores, notas de campo noviembre 2010).

${ }^{10}$ Es a partir de ese momento y del nuevo modelo pastoral cuando comienza "la diaconía indígena o embrión del clero autóctono, tan anhelado por el obispo" (Morales, 2005: 234). El diaconado indígena culmina en el año 2000, quedando muchos indígenas en proceso de ordenarse. A éstos se les denomina prediáconos.

"Uno de los aspectos "autóctonos" que sí conservan en su ritualidad e incluso comparten con otros grupos étnicos es tocar los tambores y flautas antes de ingresar a la ermita y/o "hacer caracol", es decir, una suerte de procesión circular al ritmo de los tambores (De Vos, 1997: 98; Diario de campo 2008, 2010 y 2011). 
${ }^{12}$ San Arturo Las Flores es una comunidad ubicada en Las Cañadas que llegó a ser zapatista. En la actualidad existen comunidades que se autodenominan zapatistas pero otras que ya no pertenecen al movimiento zapatista, sobre todo por cuestiones religiosas. Tuvo mucho que ver la adhesión a grupos no católicos que prohibían la participación en movimientos ateos basados en la violencia y las armas, pero también la decepción de la gente creyente porque el movimiento se burlaba de sus creencias y tampoco "cumplieron su palabra" (notas de campo, marzo 2011; Estrada, 2007: 478).

${ }^{13}$ En algunas comunidades, los proyectos de la Misión de Guadalupe se enfocan en la búsqueda de instrumentos que ayuden a frenar la devastación ecológica creando abono, composta y pesticidas a partir de productos naturales. Dan también soluciones tecnológicas sustentables para consumir menos leña; buscan mejorar la salud y la economía de las comunidades con la medicina alternativa y el fomento de la cultura de la prevención; dan educación no oficial que sea útil para su contexto; y la teología india, que no sólo busca respetar la sociorreligiosidad étnica, sino fomentar el rescate cultural en el que se incluye lo religioso, que se ha perdido por las prácticas coloniales de occidente y la misma Iglesia católica doctrinaria.

\section{Bibliografía}

Berryman, Phillip (1989), Teología de la liberación, México: Siglo XXI.

Blancarte, Roberto (1994), Iglesia y Estado en México: seis décadas de acomodo y de conciliación imposible, México: Instituto Mexicano de Doctrina Social Cristiana.

Camp Roderic, Ai (1998), Cruce de espadas. Política y religión en México, México: Siglo XXI.

Concilio Vaticano II (1966), Documentos completos del Vaticano II, México: La Nueva Librería Parroquial de Clavería.

Concha Malo, Miguel et al. (1986), La participación de los cristianos en el proceso popular de liberación en México (19681983), México: Siglo XXI.
De Vos, Jan (2004), Una tierra para sembrar sueños. Historia reciente de la Selva Lacandona, 1950-2000, México: Fondo de Cultura Económica.

De Vos, Jan (1997), "El encuentro de los mayas de Chiapas con la teología de la liberación”, en Eslabones. Revista Semestral de Estudios Regionales, núm. 14, juliodiciembre, pp. 88-101.

De Vos, Jan (1994), Vivir en frontera. La experiencia de los indios de Chiapas, México: Centro de Investigaciones y Estudios Superiores en Antropología Social.

Dussel, Enrique (1998), "Historia del fenómenos religioso en América Latina”, en Prien, Hans-Jürgen (ed.), Religiosidad e historiografía. La irrupción del pluralismo religioso en América Latina y su elaboración metódica en la historiografía, Fankfurt-Madrid: Vervuert Verlag/ Iberoamericana, pp. 71-81.

Dussel, Enrique (1995), Teología de la liberación. Un panorama de su desarrollo, México: Potrerillos.

Estrada Saavedra, Marco (2011), "Teocracia para la liberación: la disputa por la hegemonía estatal desde la fe. La experiencia de la diócesis de San Cristóbal de Las Casas y el pueblo creyente en la Selva Lacandona", en Agudo Sanchiz, Alejandro y Marco Estrada (eds.), Transformaciones del Estado en los márgenes de Latinoamérica: imaginarios alternativos, aparatos inacabados y espacios transnacionales, México: El Colegio de México/Universidad Iberoamericana, pp. $87-122$.

Estrada Saavedra, Marco (2007), La comunidad armada rebelde y el EZLN. Un estudio histórico y sociológico sobre las bases de apoyo zapatistas en las cañadas Tojolabales de la selva lacandona (1930-2005). México: El Colegio de México.

Estrada Saavedra, Marco (2004), "Construyendo el Reino de Dios en la tierra: pastoral y catequesis en las Cañadas Tojolabales de la Selva Lacandona (19601980)", en Sociológica, Año 19, núm. 55, mayo-agosto de 2004, pp. 199-242.

Gómez Hernández, Antonio et al. (eds.) (1999), Palabras de nuestro corazón. (Mitos, fábulas y cuentos maravillosos de la narrativa tojolabal), México: UNAM/UACH. 
Giménez, Gilberto (2000), "Territorio, cultura e identidades. La región sociocultural", en Rosales Ortega, Rocío (coord.) Globalización y regiones en México. México: Programa universitario de estudios sobre la ciudad, UNAM/Porrúa.

Harvey, Neil (2001), La rebelión de Chiapas. La lucha por la tierra y la democracia, México: Editorial Era.

Hernández Avendaño, Juan Luis (2006), Dios y el César. Itinerario político de la Iglesia, México: UIA/ITESO/ Plaza y Valdés.

Leyva Solano, Xóchitl (2002), “Catequistas, misioneros y tradiciones en las Cañadas”, en Viqueira, Juan Pedro y Mario Humberto Ruz (eds.), Chiapas. Los rumbos de otra historia, México: UNAM/CIESAS, pp. 375-405.

Leyva Solano, Xóchitl y Gabriel Asencio Franco (1991), "Espacio y organización social en la Selva Lacandona: El caso de la subregión Cañadas", en Anuario. Instituto Chiapaneco de Cultura. Departamento de Patrimonio Cultural e Investigación. México: Gobierno del Estado de Chiapas, Consejo Estatal de Fomento a la Investigación y Difusión de la Cultura, DIF/Chiapas, Instituto Chiapaneco de Cultura, pp. 17-49.

Mariz Cecília y Theije, Marjo (2008), "Localizing and GlobalizingProcessesinBrazilianCatholicism.Comparing Enculturation in Liberationist and Charismatic Catholic Cultures", en Latin American Research Review. The Journal of LatinAmericanStudies Association, pp. 33-54.
Marzal, Manuel (1973), “iEs posible una iglesia indígena en el Perú?”, en América Indígena, vol. XXXIII, núm. 1, enero-marzo, pp. 107-123.

Mattiace, Shannan (2001), "Regional Renegotiations of Space. Tojolabal Ethnic Identity in Las Maragritas, Chiapas", en Latin American Perspectives, vol. 28, núm. 2, marzo de 2001, pp. 73-97.

Morales Bermúdez, Jesús (2005), Entre ásperos caminos llanos. La diócesis de San Cristóbal de Las Casas (1950-1995), México: Casa Juan Pablos/UNICACH/UNICH/ COCyTECH.

Mosqueda Tapia, Eloy (2011), La lógica del campo religioso católico: desigualdad y memoria en torno al diaconado permanente indígena en la diócesis de San Cristóbal de Las Casas, Chiapas (1960-2008), México: Tesis de doctorado en Ciencia Social. Centro de Estudios Sociológicos, El Colegio de México.

Ríos Figueroa, Julio (2002), Siglo XX: muerte y resurrección de la Iglesia Católica en Chiapas, México: UNAM/ PROIMMSE.

Ruz, Mario Humberto (1992), Savia india, floración ladina. Apuntes para la historia de las fincas comitecas (siglos XVIII y XIX), México: CONACULTA.

Valtierra Zamudio, Jorge (2009), Y el Verbo se hizo carne... el proceso de inculturación y el camino hacia la autoctonía de la diócesis de San Cristóbal de Las Casas, Chiapas. México: Tesis de maestría, CIESAS. 